(C) [2009] IEEE. Reprinted, with permission, from Li, Yongjian; Yang, Qingxin; Liu, Hongxun; Zhu, Jianguo; Guo, Youguang; Xu, Wei. 2009, 'Study on a Wind-Solar Complementary Power Inverter', Proceedings of IEEE International Conference on Applied Superconductivity and Electromagnetic Devices, pp. 159-162. This material is posted here with permission of the IEEE. Such permission of the IEEE does not in any way imply IEEE endorsement of any of the University of Technology, Sydney's products or services. Internal or personal use of this material is permitted. However, permission to reprint/republish this material for advertising or promotional purposes or for creating new collective works for resale or redistribution must be obtained from the IEEE by writing to pubs-permissions@ieee.org. By choosing to view this document, you agree to all provisions of the copyright laws protecting it. 


\section{Study on a Wind-Solar Complementary Power Inverter}

\author{
Yongjian Li ${ }^{1,2}$, Qingxin Yang, Hongxun Liu \\ ${ }^{1}$ Province-Ministry Joint Key Laboratory of \\ Electromagnetic Field and Electrical Apparatus Reliability \\ Hebei University of Technology, Tianjin, China \\ yoli@eng.uts.edu.au
}

\author{
Jianguo Zhu, Youguang Guo, Wei Xu \\ ${ }^{2}$ School of Electrical, Mechanical and Mechatronic Systems \\ University of Technology Sydney \\ Sydney, NSW 2007, Australia \\ joe@eng.uts.edu.au
}

\begin{abstract}
This paper studies a wind-solar complementary singlephase sine wave power inverter, including the hardware structure, operating principle, and method to the charging and discharging design. A dual-level three-state intelligent float charging based on PIC single chip control is brought forward for combining the special characteristics of wind-solar energy system. It helps the automatic transfer between charging and discharging and active protection of the battery. Unattended wind-solar complementary power system is achieved. With the help of reasonable calculation and simulation analysis, the final parameters are determined. A prototype of $500 \mathrm{~W} / 220 \mathrm{~V} / 50 \mathrm{~Hz}$ single-phase sine wave power inverter has been fabricated. Through the model experiment the output voltage waveforms are found in conformity at both no-load and full-load, and the THD is very low. Therefore, the workability and validity are proved.
\end{abstract}

Keywords-wind-solar complementary; sine wave pulse width modulation (SPWM); dual levels three states charging; total harmonic distortion factor (THD)

\section{INTRODUCTION}

Solar energy and wind energy, two clean and renewable resources, are the best development potential natural energies in nature. They are complementary in electric power generation in the case of time and region. Wind power and photovoltaic driven stand-alone systems have turned into one of the most promising ways to handle the electrification requirements of numerous isolated consumers worldwide [1]. The Wind-solar complementary power supply system is a reasonable power supply which makes good use of wind and solar energy. This kind of power supply system can not only provide a bargain of low cost and high dependability for some inconvenient regions but also inaugurate a new way to resolve the crisis of energy sources and environment pollution [2].

It is very difficult to make use of the solar and wind energy for all-weather just through solar system or wind system individually, due to the restriction of time and region. So it is the consummate matching of solar and wind when considering the complementarity of time and region. Daytime has good illumination but poor wind energy, and when illumination weakens at night, the wind energy boosts up due to the great fluctuation of difference in temperature over the earth's surface. In the same way, backland has abundance illumination but little monsoon, and inshore is in the contrary. Fig. 1 shows the complementary characteristics between wind and solar for the whole day at a typical place. It denotes that the voltage and power curves of the solar system lie in the range of wave peak during 10:00 to 18:00 in some day, and the peak point is at about 13:00 if the solar energy is adequate enough. During this period of time, on the contrary, wind system lies in the range of wave trough and the trough point is about 17:00. The voltage and power of wind system are at the strongest range when it is at night without sunlight. So character of wind-solar complementary is obviously symbolized in this typical place. In summary, wind and solar power supply system are complementary when considering time and region, and windsolar system may be the best power supply system among the renewable energy application $[3,4]$.

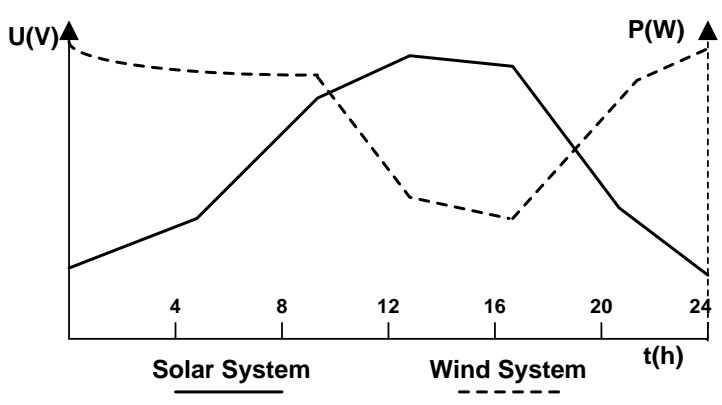

Figure 1. Wind-solar complementary characteristic at a typical place.

\section{STRUCTURE OF SYSTEM}

Fig. 2 shows the structure of the wind-solar complementary sine wave power supply system which consists of photoelectric system, wind power system, inverter system, controller, discharger, storage battery, and load, etc. The inverter system is the most important aspect of the system. Its design involves the selection and optimization of main circuit topology, calculation and selection of main switching elements, parameters consideration of transformer and filters, waveform generator, power switching isolation drive circuit, auxiliary switching power supply, detection and protection circuits, etc. The power inverter employs dual energy storage system, which includes two sets of stationary lead-acid storage battery. The active redundancy design is to improve the reliability. Full bridge topology of the main circuit is chosen for optimization of the 
incorporated design. Suppose all the power elements are ideal, i.e. the IGBT units can switch instantaneously.

The function of the discharger is: when the storage battery is fully charged, i.e. the generated energy is larger than the power consumption, in order to protect storage battery and inverter, the charger circuit connects with the discharger to dissipate extra energy. The controller, PIC MCU, samples the input signals, such as voltage, current, temperatures, to determine the system state. It can not only control the windsolar charging and discharging, but also charge the redundant battery when the preset condition is reached. Switching of two lead-acid batteries is determined by their respective voltage and performed by relays. Therefore, reasonable hardware and software design of charging and discharging controller is key part for the wind-solar complementary system.

The two power supply systems make up for each other's deficiencies. They generate energy respectively. The controller matches them to charge the battery. According to their features, the wind-solar power supply complementary gives priority to wind power supply. In addition, the complementary power supply can protect storage battery and prolong its lifetime. When wind power supply fails due to weather condition, capacity loss can not be avoided. Then, photoelectric battery will generate energy to prevent such capacity loss and prolong life [5].

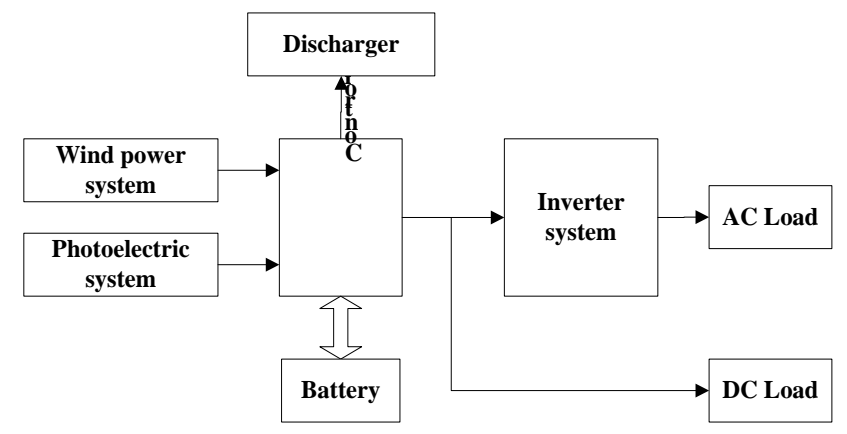

Figure 2. Diagram of a wind-solar complementary power supply system.

\section{Generation of Sine Wave Pulse Width MODULATION}

In order to increase the frequency and improve the stability of the DC/AC inverter, pure analog circuit is adopted to generate unipolar sinusoidal pulse width modulation signal [6]. Generation of the desired output wave is achieved by comparing the desired reference waveform (modulating signal) with a high-frequency triangular carrier wave, and the output wave is a set of rectangular pulse with the same amplitude and with sinusoidal trend width [5].

Reference sine wave generation circuits are composed by oscillation, frequency dividing circuit, ladder-wave synthesis, and second-order low-pass active filter circuit. By using cyclic shifting and weighting resistor synthesis, the oscillation signal can be processed and ladder signals with sinusoidal trend can be generated by synthesis of ladder-wave circuit. There are 15 ladders in one sinusoidal cycle and the voltage amplitudes of the ladders in a quarter cycle are calculated by

$$
\left\{\begin{array}{l}
U_{1}=U_{m} \sin (\pi / 8) \approx 0.383 U_{m} \\
U_{2}=U_{m} \sin (\pi / 4) \approx 0.707 U_{m} \\
U_{3}=U_{m} \sin (3 \pi / 8) \approx 0.924 U_{m} \\
U_{4}=U_{m} \sin (\pi / 2)=U_{m}
\end{array}\right.
$$

where $U_{m}$ is the DC voltage which determines the amplitude of the reference sine wave. When the active filter circuit works on the input ladder signals, high-quality reference sine wave will be available.

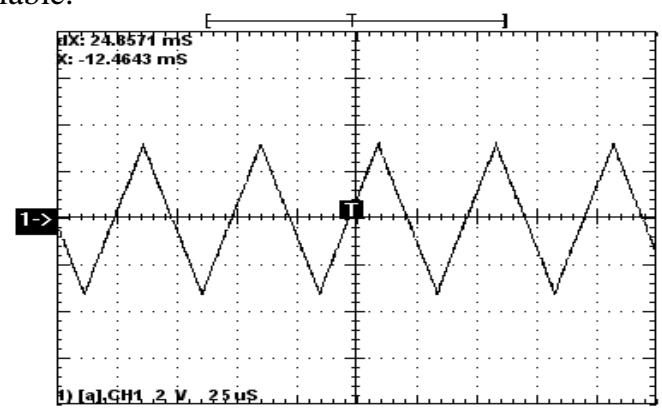

(a) Triangular carrier wave

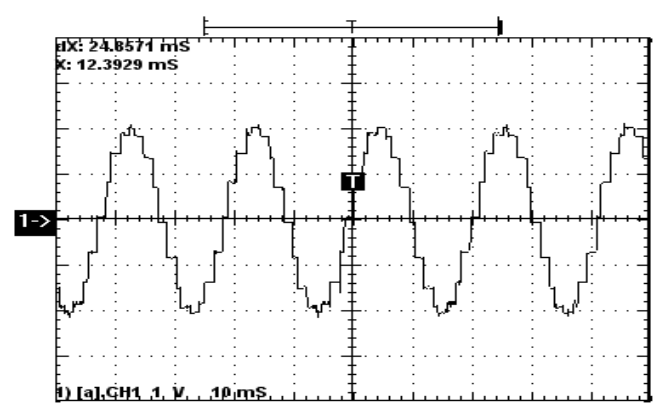

(b) Ladder wave

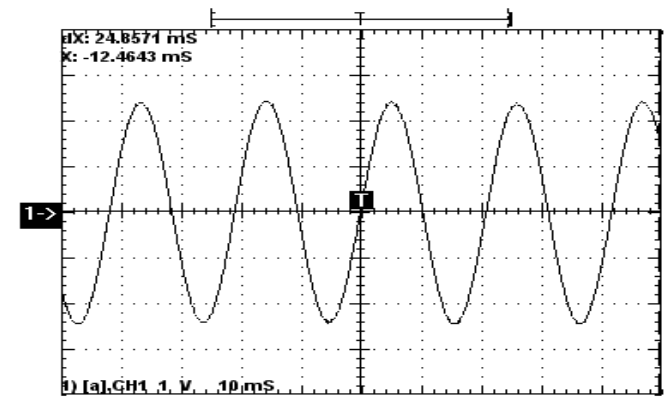

(c) Reference sine wave

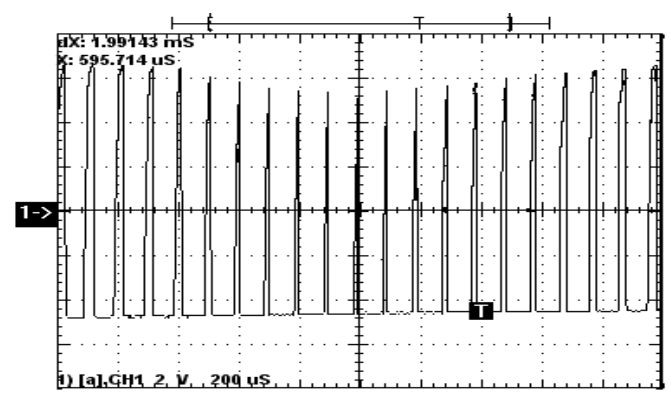

(d) SPWM wave

Figure 3. Output waveforms. 
Based on the principle of unipolar sine pulse width modulation (SPWM) [6], the output root-mean-square (RMS) voltage of SPWM can be calculated by

$$
U_{\text {orms }}=K U_{i} \sqrt{\sum_{j=1}^{p} \frac{\theta_{j}}{\pi}}
$$

where $K$ is the transformation ratio, $p$ is the number of pulses in half cycle, and $\theta$ is the width of pulse. The Fourier series expansion is

$$
u_{0}(t)=\sum_{n=1}^{\infty}\left(A_{n} \cos n \omega t+B_{n} \sin n \omega t\right) \mathrm{n}=1 、 3 、 5=1
$$

where $A_{n}$ and $B_{n}$ are the coefficients of the Fourier series expressed as

$$
\begin{aligned}
& A_{n}=\sum_{j=1}^{p} \frac{2 K U_{i}}{n \pi}\left[\sin n\left(\alpha_{j}+\theta_{j}\right)-\sin n \alpha_{j}\right] \\
& B_{n}=\sum_{j=1}^{p} \frac{2 K U_{i}}{n \pi}\left[\cos n \alpha_{j}-\cos n\left(\alpha_{j}+\theta_{j}\right)\right]
\end{aligned}
$$

where $\alpha$ is the pulse start forward angle.

The harmonic components are merely shifted into the higher frequency range and the signals generation circuits of the $20 \mathrm{kHz}$ triangular wave, $50 \mathrm{~Hz}$ ladder wave, $50 \mathrm{~Hz}$ reference sine wave and SPWM wave are designed depending on the forward analysis. The output waveforms are depicted in Fig. 3.

\section{IMPLEMENTATION OF INTELLIGENT CONTROL}

\section{A. Intelligent contral of wind-solar complementary system}

In this system, the input energy comes from battery which initially comes from wind and solar energy. Either wind turbine or solar cell has two outputs. One is connected to the storage battery by some translation circuits. The other is connected to discharger via switching relays. Switching between the wind and solar system is implemented by sensors and MCU. The detecting signal is processed by MCU, and the output signal controls the switching relays. The system parameters are determined by the maximum power load and electricity consumption per day. The maximum power load is the basis for the capacity selection of inverter. And electric energy production per day determines the capacity selection of wind turbine, solar panel and storage battery. In addition, wind and solar resources in the installation location is another important factor $[7,8]$.

\section{B. Inplementation of intelligent charging and discharging}

According to the performance, wind-solar complementary power supply system can be divided into charging state, discharging state and protection state. Meanwhile, the system can detect solar cells, wind turbine, loads and two sets of batteries. To ensure the normal operation, a dual-level threestate charging theory is introduced [9]. Dual levels indicate two criterion systems of voltage and current, while three stages are high current bulk charge state, over charge state and float charge state. The charging process is clearly shown in Fig. 4. The threshold values of voltage, current and periods of several states are set by MCU PIC16C711. According to sequencing control, status switching is implemented automatically.

Fig. 5 shows the schematic diagram of charging control circuit. MCU samples current, turbine voltage, battery voltage and temperature via $\mathrm{AD}$ ports. It controls the charging and discharging process according to the detection. Additionally, the operation state can be shown as well. Four I/O pins are configured as interface of display and keyboard input. LED display is refreshed per $50 \mathrm{~ms}$.

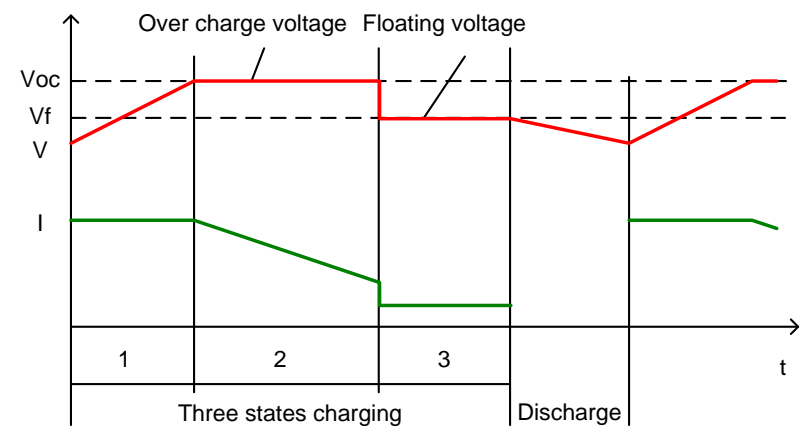

Figure 4. Process of dual-level three-state charging.

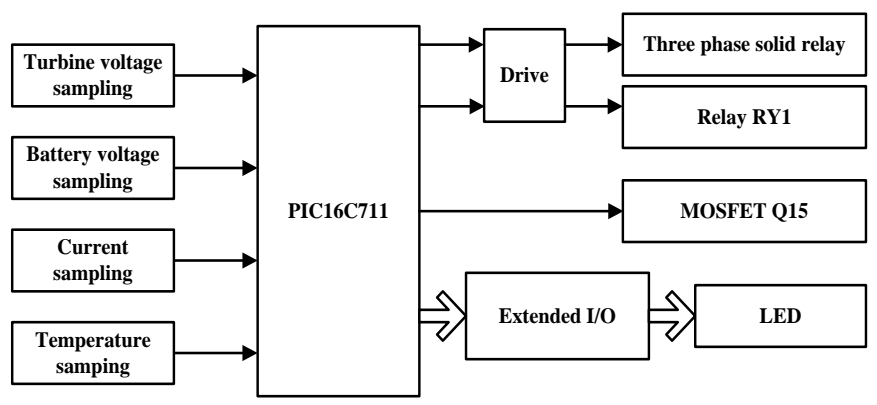

Figure 5. Schematic diagram of charging control circuit.

Fig. 6 shows the intelligent charging algorithm which is a part of the total control algorithms. Temperature of the system, as an important parameter is taken into account during the whole period of charging. Temperature and voltage signals are the basis for status switching in the system.

\section{EXPERIMENTAL RESULTS AND DISCUSSION}

\section{A. No load experiment}

A $500 \mathrm{~W} / 220 \mathrm{~V} / 50 \mathrm{~Hz}$ prototype has been developed and the control algorithm has been compiled. Under the experimental condition of good wind no sunlight, good sunlight no wind and good sunlight and good wind, the new system worked well. The output waveforms of voltage and current are shown in Fig. 7.

When there is no load, for different inputs, the output voltage waveform is sinusoidal and the THD is about $1.573 \%$. The root-mean-square voltage is $220 \mathrm{~V}$ and the current is approximately zero, as shown in Fig.7 (a). Experimental results 
show that the wind-solar complementary power supply has excellent performance when wind and solar energy changes.

\section{B. Resistive load experiment}

The rated output of designed inverter is $500 \mathrm{~W}$. For the resistive load, when $R_{L}=100 \Omega$, the inverter power is $P_{o}=484 \mathrm{~W}$, which is close to full load. When the inverter load increases, the output voltage drops a little which complies with the error specification. The waveform is sinusoidal and voltage waveform distortion is very small. The THD is about $1.348 \%$. The current waveform has the same phase with the voltage. For analysis, the current display is set reverse. When wind and solar energy change in different conditions, e.g. no load or with load, the power supply system has shown good performance.

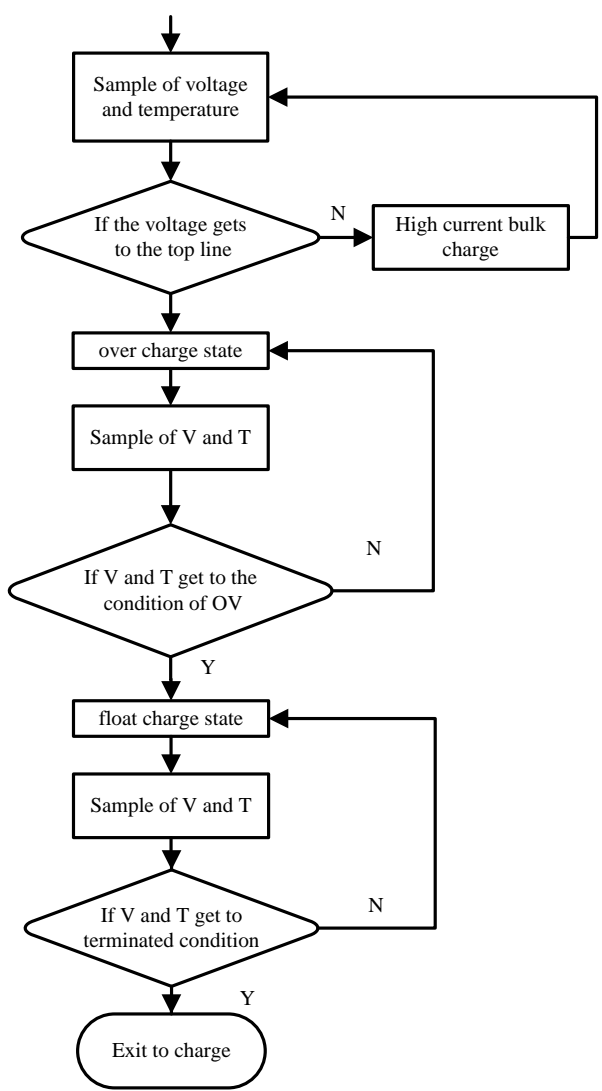

Figure 6. Algorithm of the intelligent charging.

\section{CONCLUSION}

According to the comparison experimental results, the developed wind-solar complementary power supply system has small THD, excellent steady state and dynamic response characteristics. The intelligently controlled charging and discharging based on PIC MCU plays an important role in the wind-solar complementary regulation. The design scheme is feasible and reliable. Wind-solar complementary sine inverter power supply gives good solution to the problems, such as low efficiency, high THD, difficult charging and discharging. It also provides a reference for further research on high-power wind-solar complementary sine wave power inverter with inductive or capacitive load.

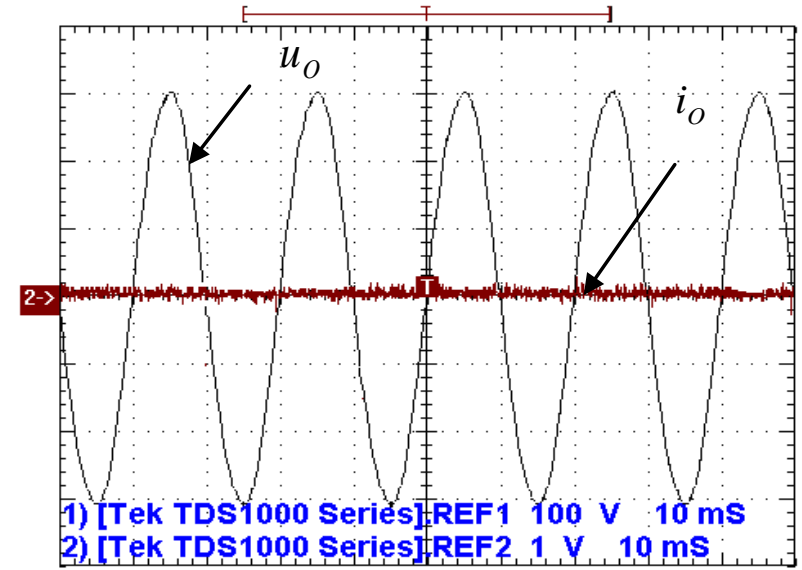

(a) No load waveform

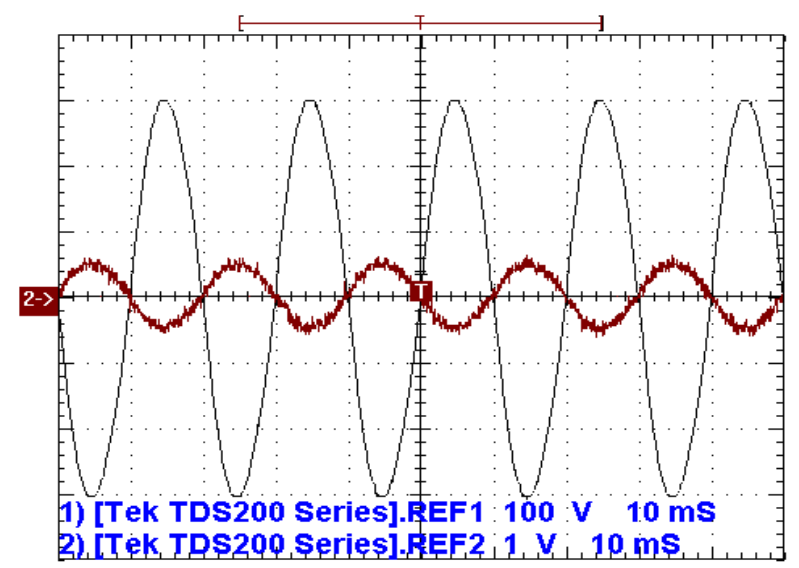

(b) Full load waveform with $R_{\mathrm{L}}=100 \Omega$ and $P_{o}=484 \mathrm{~W}$

Figure 7. Experimental waveform.

\section{REFERENCES}

[1] F. Valenciaga, and P.F. Puleston, "Supervisor Control for a Stand-Alone Hybrid Generation System Using Wind and Photovoltaic Energy," IEEE Trans. on Energy Conversion, vol. 20, No. 2, pp. 398-405, June 2005

[2] D.F. Li, "Technology and application of household 'wind-solar' complementary power system," Transactions of the CSAE, vol. 22, no. 1 (Supp), pp. 162-166, 2006.

[3] P.D. Maycock, "PV Market Update," Renewable Energy World, vol. 8, no. 4, pp. 86-99, 2005.

[4] S.D.J. McArthur, E.M. Davidson, V.M. Catterson, et al., "Multi-Agent Systems for Power Engineering Applications-Part I: Concepts, Approaches, and Technical Challenges,” IEEE Trans. on Power Systems, vol. 22, No. 4, pp. 1743-1752, November 2007.

[5] Y.J. Li, Y.F. Liu, B. Liu, and X.Y. Mi, "Research of wind-solar complementary sine wave power inverter,” Journal of Hebei University of Technology, vol. 37, no. 4, pp. 71-76, 2008.

[6] D.L. Chen, and L. Li, "Bi-polarity phase-shifted controlled voltage mode AC-AC converters with high frequency AC link,” in Proc. IEEE PESC, 2003, pp. 677-682.

[7] C.J. Zhao, J.H. Yang, Z.H. Chen, and Q.L. Zou, "State \& development of photovoltaic application,” Energy Conservation Technology, vol. 25, no. 5, pp. 461-465, 2007.

[8] C. Matevosyan, and T. Bolik, "International comparison of requirements for connection of wind turbines to power systems,” Wind Energy, vol. 8, no. 3, pp. 295-306, 2005.

[9] C.A. Ji, X.B. Zhang, B. He, G.H. Zeng, and X.L. Zhou, "Photoelectric control system based on MCU," Control \& Automation, vol. 21, no. 3, pp.46-47, 2005. 